\title{
Science and Technology to Change Human Being's Behaviour According to Quran as Counselling Approach
}

\author{
$1^{\text {st }}$ Elfi Mu'awanah ${ }^{1}, 2^{\text {nd }}$ Rifa Hidayah ${ }^{1}, 3^{\text {rd }}$ Sulistyorini $^{1}, 4^{\text {th }}$ Munardji $^{1}, 5^{\text {th }}$ Umy Zahroh $^{1}$ \\ \{elfimuawanah@iain-tulungagung.ac.id ${ }^{1}$,rifahidayah@uin-malang ${ }^{1}$, sulistyorini@iain- \\ tulungagung.ac.id ${ }^{1}$, munardji@iain-tulungagung.ac.id ${ }^{1}$, umyzahroh@iain-tulungagung.ac.id ${ }^{1}$ \}
}

IAIN Tulungagung, East Jawa, Indonesia ${ }^{1}$

\begin{abstract}
The purpose of this study is to analyse the behavioral science and technology as a reference for counseling clients. It concerns with the discovery of methods of changing human behavior in order to be one of the approaches to improve human happiness. When human conducts deviant behavior, he has been hurt even though in reality he seems to hurt others, so in fact he hurt himself. So by finding the pattern of technological change of behavior in the Quran then it shows the real practice of successful behavior change. When a person has succeeded in turning into a good behavior, he can keep the goodness and he will grow as well as make himself beneficial for himself and others. Behavioral changes must be properly spoken and practiced by the client as an indicator of behavioral change. Changing behavior does not only happen for a moment but the client should make his or her behavior a new style in his life. Thus the success of changing behavior in the context of counseling belongs to technology for human improvement, which is as good as the technology of other fields that are also born for the benefit of human beings.
\end{abstract}

Keywords: behavior change; counseling approach; science and technology;Quran

\section{Introduction}

There are several studies on science and technology and according to the discipline of each expert. There are expert exact and social experts in the development of science. All discoveries in the field found by the researchers is appropriate discipline [1] science is expected to provide benefits for the development of science. Here are some topics of research conducted by experts in their respective fields. In technological developments, research has been conducted on physics by scientists with the discovery of certain chemical formations. In recent advances in high-pressure science and technology, about the boom of high -pressure science and technology from a small niche field to become a major dimension in physical sciences. One of the most important technological advances is the integration of synchrotron nanotechnology with the minute samples at ultrahigh pressures.

Likewise, research in the development of this technology processing focuses on several risk management issues in coal science and technology and risk management companies applying methods comprehensively to provide scientific theoretical foundations and methods that can operate for risk management [2]. This research focuses on several risk management 
issues in coal science and technology firms and risk management that apply the method comprehensively to provide a scientific and operational theoretical basis for risk management.

Similarly, there are also scientists who examine the exact scientist printing institutions [3] where he examined the single sex school enhancing students STEM (Science, technology, engineering and mathematics) outcomes and found male sex just better results than the female sex itself is school science and technology. Male gender factors for science, technology, engineering and mathemathic majors in educational institutions affect the choice of school majors and the results of graduates of this science-printing school. While [4] research in science and engineering and engineering institute enhanced cooperation to produce students who can build network post-school work. Subsequent research related to green science as a high-level building design technology to reduce energy and the environment research results is a simple engineering application of high energy physics reactions and produces clean energy and is a leading edge technology [5].

Research related to science and technology park is a productive activity done by collaborating government, academia, community and business [6]. That it is important to create stakeholder excellence that generates innovation by optimizing human resources, the power and goodness of public policy. Scientific research on the status of the awards of science and technology of Chinese nursing associations and the analysis of the development trends of nursing research in which scientific research is predicted to contribute to human health given the current state of human aging [7].

Scientific research highlighting science and technology institutions as a form of management participation in a sustainable practice that can be replicated in society and off campus with this study is expected to use IMS as an evaluation framework as needed . Scientific and technological research in Japan as the first country to establish the regulation of health system security in the world by involving trained neutral academic researchers and experts in the field of consumer and functional food science regulation as trends in food science and technology [8]. Undertook carbon storage research to advance science and technology to support commercial deployment [9]. Similarly, science research for development as well as the step and convergence of science technology development with political policy and adapted to economic development respond the need for more sophisticated techniques in research in science [10]. It also promotes scientists to take special follow-up to detect important variables in environments that may be significant for future success of the area analyzed in this study [10].

Subsequent research related to open innovation is known as the use of purposive inflows and outflows with the aim of accelerating the company's internal innovation and expanding markets through the use of external innovation is a vital window of opportunity for all companies to compete with technology and survive. Companies that face many things to engage in open disclosure may be a closed-door intent and are reluctant to use open innovation in open innovation to understand the factors, which are disincentives to open innovation appropriately. Corporate secrecy and confidentiality, human resources, brand and image, resources and costs, organizational management, market equity, technology and administration resources are carried out [11]. An important study of a model for investigating stability factors in collaborative networks of formal science and technology is a case study on Iran [12] as research in a network of collaboration in the realm of science and technology, organization, long-term stability in one of the main expectations on the founding of a network of developing countries such as Iran where government and public institutions are major contributors in the investment network. 
The next research conducted [13] on defense investment and the transformation of national science and technology, the perspective of high-tech exploitation, the dollar of national defense positively correlates with national-scale productivity in the article but does not correlate with the national defense dollar patent positively moderates patent technology but negatively softening the application of scientific articles for the development of economic products. In the analysis of US dollar defense moderation seems to be in a relatively favorable position compared to the most advanced OECD economies. Similarly, research conducted [14] and devised a national science and technology evaluation system based on a new international practice typology. The gap analysis of the optimistic and optimistic situation of the Iranian S \& T evaluation system shows that primarily on key system functions, interaction framework and financing dimension models, significant changes must occur through the application of evaluations. So is the research of public involvement models employed by science communicator firms that focus on the dissemination of engineering and mathematical engineering (STEM) knowledge with learner subjects. It examines the potential of science shows to foster the interest and imagination of young learners in STEM discussions that focus on conversations with members of science and science education based in the UK and universities and the conditions necessary for the success [14].

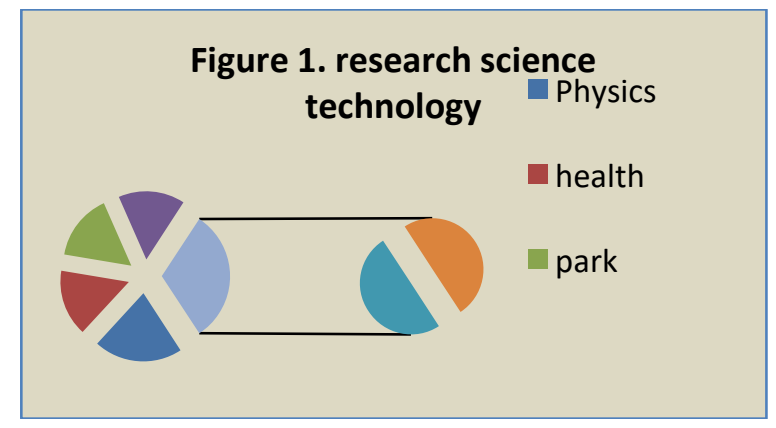

Figure 1. Research Science Technology

The above research (figure 1) is very useful both in the context of natural resource empowerment, maintaining nature, especially human life and goodness in general. The author looks at how the human condition itself in which in his life he behaves experiencing barriers to gain happiness and achieve advancement in technology and science that he should be able to master and enjoy. It is necessary to find the technology of behavior change that prevents the attainment of happiness in one's own life, especially also for the utilization of others. The authors argue that there is a science of technology that works specifically for human happiness associated with itself as a connoisseur of the times. Previous research is related to exact science research. It needs more exploration on the science of knowledge and technology related to the change of behavior.

Counseling is a science and technology altering behavior itself is a separate discipline study is also an important existence in order to provide help to someone who hampered to get happiness himself and also others. Counseling is a technology that concentrates on changing behavior. The result can make a person can improve the knowlege on his respective disciplines. If technology and science in the exact, health, and social fields were created by human beings, what about the technology created by the human creator, God. In Islam there is a technology of behavior change written in the Word of God as a source of knowledge. 
Considering all of the above suggestions stating that Islam has an important effect on most Muslims, some Muslim counselors will have their wish to use their belief system to get over their issues [15]. How the two Muslims clients held a strong belief and were tried to put it into practice in their daily life and also in the counseling sessions.

Through the Quran any behavior that can prevent people from doing good for themselves as well as others. The implications of this study are predicted to provide examples of how such behaviorally altered systemic behavioral technology can be a scenario for other behaviors, in which humans are the object of the technology of behavior change itself.

\section{Literature Review}

In behavioral change technology or called counseling there are several studies that show that with certain technologies one can be helped to improve the quality of life through cognitive-behavioral approach as did [16] and successfully changed his behavior to more positive. Counseling can help a person with interpersonal sensitivity issues, such as [17] through a behavioral cognitive approach. Similarly, there is providing weight management counseling is cited as a reason for limited tratment through cognitive behavioral counseling as the [18]. Behavior modification technology is also addressed to someone who is an alcoholic and a sex offender in the opinion of [19] becomes a descendant of alcohol and sex addiction. Next research of [20] enhances women's courage ability to give birth to the risk of childbirth through an Internet-based behavioral cognitive approach. To clients who experience behavioral disorders can also be changed through the cognitive approach of behavioral counseling and therapy as research [21]. In addition there are studies related to behavioral cognitive counseling to reduce anxiety by [22] through practice to students. A behavioral cognitive counseling approach to reduce depressed childhood parental divorce as [23]. There is also [24] conducted research to change the behavior or counseling of clients who fear the risk of cancer becomes bold against the risk of disease.

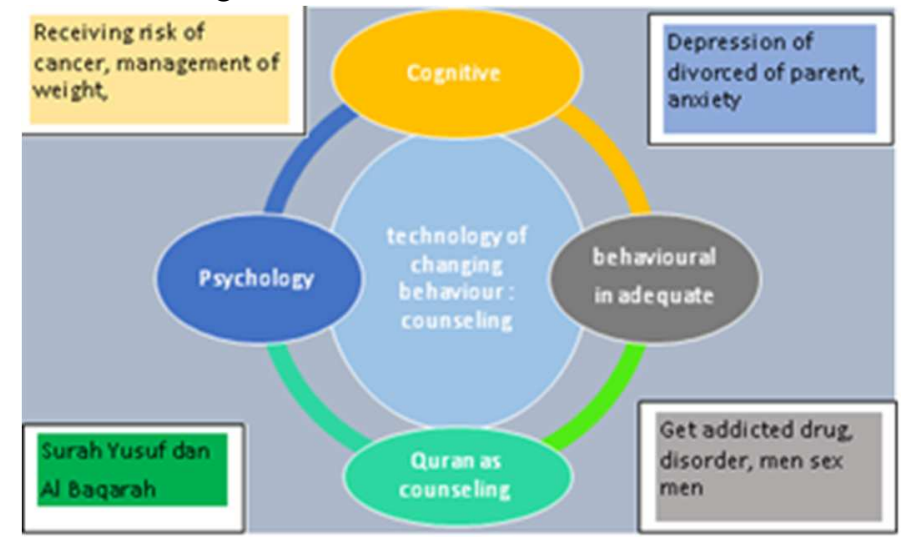

Figure 2. Posisition Technology: Counseling as Changing Behaviour on Reasearch Studies

On the role of psychology and social science in effective spiritual and religious medicine, Muslim scholars emphasize "holistic medicine" that involves psychological, physical and moral aspects [25]. The theological and philosophical debates of spiritual and health problems within the Quran encourage Muslim scientists and spiritual nurses to think of the existence, 
the nature, the quality of the afterlife and their influence on human nature. Likewise, taking the Quran as an example of knowledge in human life can be used as a model of positive behavior in the life of an individual. This research is directed to bridge the latest technology today. Figure 2 shows the current research position is technology behavioral reproduction taken from the main source of Islamic teachings that is Quran.

\section{Methods}

Constant comparative method by constructing the ground theory from collecting and analyzing empirical data, comparing the whole process with the first stages comparing the prevailing events of each category, secondly integrating the categories and their properties, the third limiting theory and the fourth writing theory of Jupp V [26]. Potter explains that constant comparative is done by catagery entitlement stage, stake inoculation, corroboration \& consessus, and active voicing [26].

The steps of historical research are done by determining the problem, declaring the purpose, hypotetesis and reseach question, collecting data, evaluating the data of both external and internal carbon dating of artefacts, reporting the results of Sukardi's research [27] especially the history of the story in the Qur'an. Category entitlement is done by categorizing discourse in Quran texts related to technology of behavior change, stake inoculation is done by studying the contradiction and diction of words in Quran, corroboration \& consensus in common of all new behaviors expressed nature of Quran word discourse, and active voicing collecting words in Quran with quote verses, showing indications in the Quran to corroborate research findings.

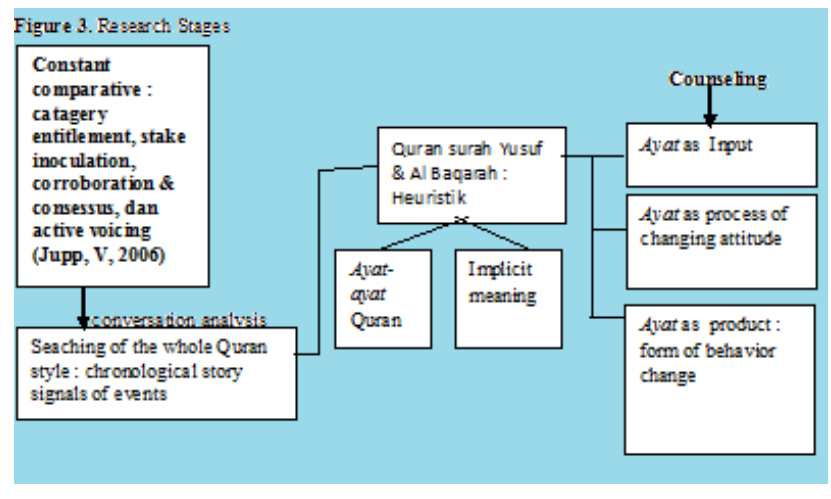

Figure 3. Research Stages

Conversation analysis, also carried out in this study of any verbal and non verbal expression as well as behaviors that appear in the word Quranic verses related to behavior change technology [26]. In addition, the research also uses a heruistic approach. In applying heuristics ignores the completeness or perfection of the text or grammatical conditions. So that researchers can mean and conditions when the Quran is derived also the culture, inner experience, culture or imagination through Quranic verses by researchers [27] The work of 
heuristics produces a literal understanding of meaning, explicit meaning, actual meaning contained in the Quran.

Heuristics, is a step to interpretation by reference through linguistic signs. In this case researchers are expected to give meaning to linguistic forms that may not be grammatical (ungrammaticalities). Researchers assume that language is referential, in the sense that language must be related to the real thing. The realization of a heuristic reading can be either the Quranic verses used or the messages put forward in the context of counseling. The indication of the verse that characterizes counseling follows the following guidelines in accordance with the completeness of science and technology counseling.

Table 1. Instruments of Heuristic Study QS Yusuf Counseling: Adaptation

\begin{tabular}{|l|l|}
\hline No & The dynamics of change \\
\hline 1 & Who changes (in put): the process of behavior \\
\hline 2 & Circumstances before changing \\
\hline 3 & Behavior change technology: counseling (process) \\
\hline 4 & Product (Change of behavior) \\
\hline 5 & The process of changing ways and atmosphere \\
\hline 6 & Who conducts and stimulates behavioral changes \\
\hline
\end{tabular}

Microethnography is used because this study studies what is heard and bound to the details of human interaction and its activities are told in the Quran. Document analysis used in this research there is a history of asbabun nuzul in the Quran shaped word written in the Quran including social functions, interpretation, effects and use penafsran associated with the Quran context [27]. In addition, this study also conducts discourse analysis contained in the Quran. As well as discourse analysis is done by revealing knowledge in the Quran and then designed in theory and practice of certain behavior discourse is occasioned, action oriented, and contructed.

Furthermore, this study also undertaken the study of individual and group behaviors that perform extreme behavior and result in life-threatening others contained in the story in the Quran [27]. Data archives are conducted by acquiring, storing and disseminating data in the Quran for secondary analysis of research and preserving the long term that can be guided as well as cultural studies conducted in this research as a cross-disciplinary effort in expressing the world's place and cultural significance in all forms of "culture in the Quran" Clear and concise elaboration of the method applied and the steps taken to ensure the reliability and validity of used methodology. Explain the sample and target population with justifications in the form of Quranic verses containing the chronology of an event thoroughly and completed in the letter of Joseph using the instruments of Table 1.

Hypotheses of this research is that there is technology in the Quran letter, especially the letter of Joseph, there are inputs in the form of deviant behavior and behavioral change technology in the form of behavioral cognitive counseling as well as technology products that change behavior in the form of new behavior that becomes better than the previous behaviour.

\section{Results and Discussion}


The discovery of behavior change technology is found by researchers in the Epistle of Joseph, where it is narrated in the Quran that there is a conflict of siblings of the Prophet Yusuf. A family conflicted and formed two groups, the first group of Prophet Yusuf and Benjamin, the second group of 10 brothers Joseph. Facing the risk of conflict has many siblings with family members. What behaviors need to be changed, how does the behavior change system in Joseph's letter. What guidance and counseling needs to be strengthened during a behavior change system. Here is a picture found by related researchers.

The feelings of someone who wants something to happen to him and it does not happen to him is a problem. In the above event it seems that the problem triggered by the client's desire to get the affection of his father was not given to him but given to others who did not want. Client feels entitled to affection because they feel superior to others .... (QS12: 8). From this incident if the client can control his main emotions, thoughts (QS12:10 QS 14:17) and deeds (QS 12:16,18) and his actions will behave healthfully, otherwise he will behave deviate. The results of behavior change based on QS 12 technology of behavior are

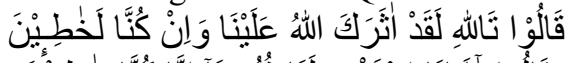

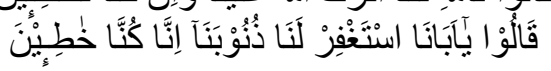

Acknowledging the strengths of others and acknowledging God who has favored Yusuf of them from hating others to wanting to kill through QS 12 science and technology is changing behavior. The step science and technology QS 12 is below.

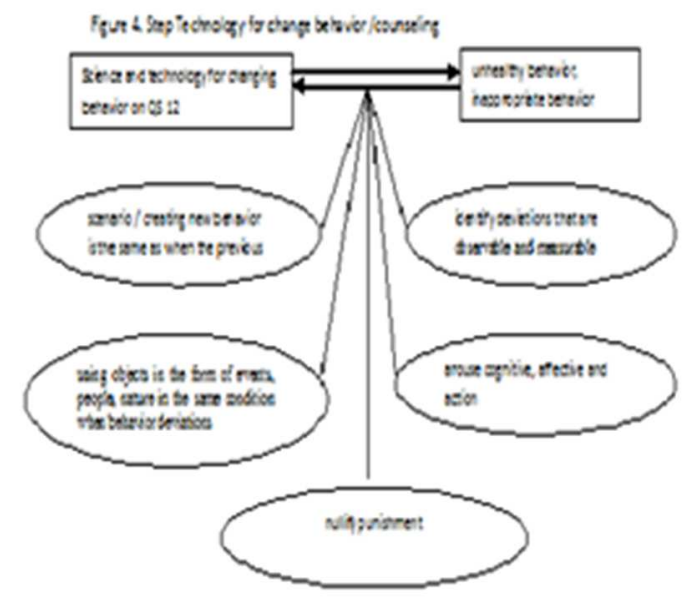

Figure 4. Step Technology fo Change Behaviour/Counceling

Technology to change behavior in surah Yusuf is a story directly told by God as an example to design new behavior. In accordance with Beck counseling theory that deviant behavior can be restructured back into good behavior or not deviate. Given the positive behavior change in surah Yusuf marks the indication of the success of the counseling process which also requires several stages to be able to change one's behavior. The process of cognitive awareness as a technology of behavior change seems to be predicted by researchers as a key to encourage affection client to transform himself into a good person. The habit of 
doing negative actions in problem and by client in such a way through this behavioral change technology has become a new person through the stages deliberately changed the behavior of client by "counselor" so that the behavior is consistent and become a new "style" for the client make his new behavior becomes character him.

Client perform deviant behavior has a purpose to seize parental love. So the client does everything that anyone who he thinks obstructs his desire to get his parents' affection should be eliminated. The process of "counselor" is to analyze what behaviors a client needs to promptly modify behavior [17].

The implementation of QS Yusuf for changing behavior through proposive sampling of children who have negative behavior stealing the age of 11 years.

\subsection{Diagnosis}

There are 11-year-olds, trapped in stealing behavior. he lived only with a single parent because of divorce with his wife. the client stole more than $5 \mathrm{HP}$ of cellphone. the economic condition of the parents of this child is very poor. The school's condition for the child did not pass grade 6 and was forced to change schools because they had to repeat grade 6 .

\subsection{Prognosis}

The main behaviors that need to be changed for clients are stealing habits. how to change the habit of stealing to not stealing. The main behaviors that need to be changed for clients are stealing habits, how to change the habit of stealing to not stealing.

\subsection{Treatment}

Tabel 2. Treatment

\begin{tabular}{|c|c|}
\hline $\begin{array}{l}\text { 1.Identify deviations } \\
\text { that are observable } \\
\text { and measurable }\end{array}$ & Steal \\
\hline $\begin{array}{l}\text { 2. Scenario / creating } \\
\text { new behavior is the } \\
\text { same as when the } \\
\text { previous }\end{array}$ & $\begin{array}{l}\text { Contacting the village head, neighborhood head, } \\
\text { school principal, father of the child, the unit } \\
\text { where this child learns martial arts together } \\
\text { oversees this child's behavior. Provide } \\
\text { cooperation so that this child is aware that God is } \\
\text { watching his behavior. if it doesn't stop now from } \\
\text { stealing behavior, will its life continue like that. } \\
\text { Adults will become thieves arrested by police or } \\
\text { beaten up. Self-management to not get something } \\
\text { in a fast and unclean way of stealing is brought to } \\
\text { the fore to change to the right work, hard work to } \\
\text { reach a halal fortune in the future. All parties } \\
\text { motivate this child to be diligent in school } \\
\text { because school is one place to break negative } \\
\text { behavior. Therefore this child should stop being a } \\
\text { thief. }\end{array}$ \\
\hline $\begin{array}{l}\text { 3. Using objects in } \\
\text { the form of events, } \\
\text { people, nature in the } \\
\text { same condition } \\
\text { when behavior } \\
\text { deviations }\end{array}$ & $\begin{array}{l}\text { Contacting the village head, neighborhood head, } \\
\text { school principal, father of the child, the terate } \\
\text { heart unit where this child learns martial arts } \\
\text { together oversees this child's behavior }\end{array}$ \\
\hline $\begin{array}{l}\text { 4. Arouse cognitive, } \\
\text { affective and action }\end{array}$ & 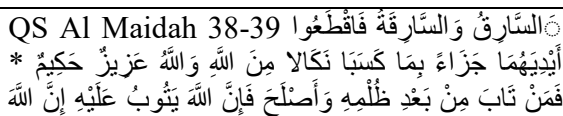 \\
\hline
\end{tabular}




\begin{tabular}{|c|c|}
\hline & غَفُورُ رَحِيمُ \\
\hline $\begin{array}{l}\text { 5. Nullify } \\
\text { punishment }\end{array}$ & $\begin{array}{l}\text { Does not give a chance to steal again. At } \\
\text { home he is given more attention and no } \\
\text { money is available to him }\end{array}$ \\
\hline
\end{tabular}

\subsection{Follow Up}

Every week or month the client is given homework to control the desire, and adjust according to his needs as a child. When mocked by a friend as a thief he responds "yes I was a thief but now I want to be a pious child". It is supported by his father to return to the way of Allah by exemplifying kindness and orderly worship for this child.

\section{Conclusion}

Although client has sense and sense is one way his body learn about the word, [29], it needs changing the behavior through the use of all five senses to gain knowledge in learning science including learning new behaviors. And all the sensory capacities should also be considered by the counselor whether the client has truly functioned all these senses in order to receive all the messages of change in himself. A company needs to invoke the most fundamental bases of action: the attitude and behavior of its people [30]. It is also necessary to apply to the client so that he or she can maintain a commitment to be good at maintaining well-behaved behavior. All of the element affecting the bottom-line performance, the importance of the leader's mood and behavior are most suprising. The leader of moods and behaviors drives the moods and behaviors of everyone else, it does not inspire counselors to keep the spirit of helping the client in whatever condition he is in.

If the counselor wants the client like most succesful leaders, the counselors are in the early stages of their plan career, given plenty of guidance and support [31]. Psychologist mentions that there are two processes of thinking alghoritmic linear thinking process and convergent straight toward a certain target [32]. Both think heuristic thinking diverges toward multiple targets at once.

In visual search procedure of research, it ideally begins with identification, general description, mathematical description, historical testing, if accept appropriate identification continue research to answer, if not appropriate proceed to disccard and repeat modify mathematichal description [33]. The strengths and contribution of research to theory that the counseling in Quran Yusuf verses can be used as a counseling model to handle the behavior of the counselor as well as build the commitment of counselor to defend himself not to give punishment to the client. When the counselor identifies deviant behavior and the counselor remains positive thinking to all the client's efforts, it is showing the desire to change for the better. Contribution in counseling practice is done using behavioral modification model which should follow the behavior change scenario gradually to increase the result of changing. The limitation of this study is on behavioral forms that can be observed and measured so that for hidden behavior may not be altered in this process. Future research directions with the conclusion that the model of behavioral change technology can be extended to other Quranic verses or sources of Islamic teachings or other religious teachings.

Acknowledgement. This paper in conjuction with The 1st International Conference on Islam, Science and Technology (ICONIST 2018) in Malang, East Java. 


\section{References}

[1] H. K. Mao et al., "Recent advances in high-pressure science and technology," Matter Radiat. Extrem., vol. 1, no. 1, pp. 59-75, 2016.

[2] B. Fan and Y. Yuan, "Constructing an assessment index system for strategic risk management in coal science and technology enterprises," Int. J. Min. Sci. Technol., vol. 26, no. 4, pp. 653-660, 2016.

[3] H. Park, J. R. Behrman, and J. Choi, "Do single-sex schools enhance students' STEM (science, technology, engineering, and mathematics) outcomes?," Econ. Educ. Rev., vol. 62, no. October 2017, pp. 35-47, 2018.

[4] Á. R. Vásquez-Urriago, A. Barge-Gil, and A. Modrego Rico, "Science and Technology Parks and cooperation for innovation: Empirical evidence from Spain," Res. Policy, vol. 45, no. 1, pp. $137-$ $147,2016$.

[5] M. Hosain F, "Green Science; Advanced Building design technology to mitigate energy and envirenment.," IInternational J. Renew. Suistainable, vol. xx, pp. 1-10., 2017.

[6] Z. S. Kusharsanto and L. Pradita, "The Important Role of Science and Technology Park towards Indonesia as a Highly Competitive and Innovative Nation," Procedia - Soc. Behav. Sci., vol. 227, no. November 2015, pp. 545-552, 2016.

[7] B. Wang, Q. Yan, Q. Zhu, N. Zeng, Z. Yu, and H. Wang, "Status of the Science and Technology Award of the Chinese Nursing Association and analysis of the development trend of nursing research," Int. J. Nurs. Sci., vol. 3, no. 3, pp. 223-228, 2016.

[8] N. Tanemura, N. Hamadate, and H. Urushihara, "The need for consumer science and regulatory science research on functional foods with health claims - What should we do to harmonize science and technology with society?," Trends Food Sci. Technol., vol. 67, pp. 280-283, 2017.

[9] T. Rodosta, G. Bromhal, and D. Damiani, "U.S. DOE/NETL Carbon Storage Program: Advancing Science and Technology to Support Commercial Deployment," Energy Procedia, vol. 114, no. November 2016, pp. 5933-5947, 2017.

[10] J. Guadix, J. Carrillo-Castrillo, L. Onieva, and J. Navascués, "Success variables in science and technology parks," J. Bus. Res., vol. 69, no. 11, pp. 4870-4875, 2016.

[11] K. Şimşek and N. Yıldırım, "Constraints to Open Innovation in Science and Technology Parks," Procedia - Soc. Behav. Sci., vol. 235, no. October, pp. 719-728, 2016.

[12] R. Asadifard, S. H. Tabatabaeian, J. B. Sofi, and M. R. Taghva, "A model for investigating the stability factors in formal science and technology collaborative networks: A case study of Iran," Technol. Forecast. Soc. Change, vol. 122, pp. 139-150, 2017.

[13] T. H. Malik, "Defence investment and the transformation national science and technology: A perspective on the exploitation of high technology," Technol. Forecast. Soc. Change, vol. 127, no. September, pp. 199-208, 2018.

[14] S. Ghazinoory, M. Farazkish, G. A. Montazer, and B. Soltani, "Designing a national science and technology evaluation system based on a new typology of international practices," Technol. Forecast. Soc. Change, vol. 122, no. April, pp. 119-127, 2017.

[15] Cashwell, C. S., Young, S., Fulton, C. L., Willis, B. T., Giordano, A., Daniel, L. W., Crockett, J.,Tate, N., \& Welch, M. L., "). Clinical behaviors for addressing religious issues: Dowe practice what we preach?," Int. J. Couns. Values, vol. 58, pp. 45-58., 2013.

[16] B. L. \& Alizadeh, "The Effect of Cognitive-behavioral setress management training on improving psychological symtoms and Quality of Life in Nurses.," J. Res. Heal. Soc. Dev. Heal. Promot. Res. Cent., vol. (7), 2017.

[17] D. Hiçdurmaz and F. Öz, "Nurse Education Today Interpersonal sensitivity , coping ways and automatic thoughts of nursing students before and after a cognitive-behavioral group counseling program," YNEDT, 2015. 
[18] J. K. Ockene et al., "Design and rationale of the medical students learning weight management counseling skills (MSWeight) group randomized controlled trial," Contemp. Clin. Trials, no. April, pp. 0-1, 2017.

[19] G. Santos et al., "Substance use and drinking outcomes in Personalized Cognitive Counseling

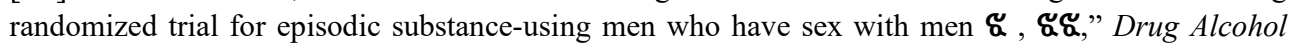
Depend., vol. 138, pp. 234-239, 2014.

[20] E. Ternström et al., "Sexual \& Reproductive Healthcare A randomized controlled study comparing internet-based cognitive behavioral therapy and counselling by standard care for fear of birth - A study protocol," vol. 13, pp. 75-82, 2017.

[21] I. Shubina, "Counseling and Therapy of Patients with Behavioural Disorders Using the Cognitive-behavioural Approach," Procedia - Soc. Behav. Sci., vol. 217, pp. 1008-1018, 2016.

[22] E. Zarei, A. Akbar, and S. Fini, "A comparison of Effect of group counselling methods, behavioural , cognitive and cognitive- behavioural to reduce students Test anxiety in the University of Hormozgan," vol. 5, pp. 2256-2261, 2010.

[23] S. Karami, A. Ghasemzadeh, M. Saadat, E. Mazaheri, and T. Zandipour, "Effects of Group Counseling with Cognitive-Behavioral Approach on Reducing Divorce Children's Depression," Procedia - Soc. Behav. Sci., vol. 46, pp. 77-81, 2012.

[24] V. . Albada, A, Ausems GEM, M, Dulmen, "International Journal of Social Science \& Medicine," Couns. Particip. Follow. breast cancer Genet. Couns. Visit Assoc. with achevment Prefer. role, Cogn. outcomes, risk Percept. aligment perceived Pers., vol. 1, 2014.

[25] N. Isgandarova, "Effective Islamic spriritual care: Fundations and Practices of Imams and other Muslim Spriritual Caregivers," in Library and Achieves, Heritage Branch Otawa, Canada: Library and Achieves, Heritage Branch Otawa, 2011.

[26] V. T. S. L. : S. P. Jupp, Dictionary of Research Methodes. London: The Sage London, 2006.

[27] Sukardi, Educational Research Methodology. Jakarta: Bumi Aksara, 2014.

[28] M. Elfi, Islamic Counseling Guidance Understanding the phenomenon of juvenile delinquency and choosing its approach to Islamic counseling. Jogjakarta: Teras, 2012.

[29] F. S.M, Rourke's World of Science Encyclopedia. Florida: LCC, 2011. Water in South Kalimantan," IOP Conference Series: Earth and Environmental Science, vol. 175, no. 1, pp. 012007, 2018. 